\title{
Flexural Strengthening of RC Slabs Using a Hybrid FRP-UHPC System Including Shear Connector
}

\author{
Jiho Moon, ${ }^{1}$ Mahmoud M. Reda Taha, ${ }^{2}$ and Jung J. Kim ${ }^{3}$ \\ ${ }^{1}$ Department of Civil Engineering, Kangwon National University, Chuncheon-si, Gangwon-do 24341, Republic of Korea \\ ${ }^{2}$ Department of Civil Engineering, University of New Mexico, MSC01 1070, Albuquerque, NM 87131-0001, USA \\ ${ }^{3}$ Department of Civil Engineering, Kyungnam University, 7 Kyungnamdaehak-ro, Changwon-si 51767, Republic of Korea
}

Correspondence should be addressed to Jung J. Kim; jungkim@kyungnam.ac.kr

Received 11 April 2017; Accepted 7 May 2017; Published 5 June 2017

Academic Editor: Doo-Yeol Yoo

Copyright (C) 2017 Jiho Moon et al. This is an open access article distributed under the Creative Commons Attribution License, which permits unrestricted use, distribution, and reproduction in any medium, provided the original work is properly cited.

\begin{abstract}
A polymeric hybrid composite system made of UHPC and CFRP was proposed as a retrofit system to enhance flexural strength and ductility of RC slabs. While the effectiveness of the proposed system was confirmed previously through testing three full-scale one-way slabs having two continuous spans, the slabs retrofitted with the hybrid system failed in shear. This sudden shear failure would stem from the excessive enhancement of the flexural strength over the shear strength. In this study, shear connectors were installed between the hybrid system and a RC slab. Using simple beam, only positive moment section was examined. Two full-scale RC slabs were cast and tested to failure: the first as a control and the second using this new strengthening technique. The proposed strengthening system increased the ultimate load carrying capacity of the slab by $70 \%$, the stiffness by $60 \%$, and toughness by $128 \%$. The efficiency of shear connectors on ductile behavior of the retrofitted slab was also confirmed. After the UHPC top is separated from the slab, the shear connector transfer shear load and the slab system were in force equilibrium by compression in UHPC and tension in CFRP.
\end{abstract}

\section{Introduction}

Every year, more concrete is used in construction than any other material. In 2010, concrete produced in United States has been estimated to be worth $\$ 35$ billion [1]. The widespread use of concrete can be attributed to its attractive properties and accessibility. Because of its poor tensile strength, it is paired with reinforcing steel, which is cast away from the neutral axis, to form an effective composite. This composite, reinforced concrete (RC), is designed such that the compression forces are resisted by the concrete while the tension forces are resisted by the steel. This configuration of reinforcement provides acceptable flexural strength for RC.

$\mathrm{RC}$ is used in structures of all types, ranging from columns, beams, slabs, and foundations. Because of deterioration of the concrete due to aging, corrosion of the reinforcing steel, and increased loads that were previously unaccounted for, structural members may require strengthening after being constructed [2-5]. Moreover, due to the concern for blast-resistance of RC structures, strengthening of existing RC structures has become an important topic in structural engineering $[6,7]$.

If strengthening existing infrastructures is feasible, it is much preferred over the demolition and construction of an entirely new system. This is due to the relatively low cost of strengthening compared to new construction in addition to the minimal impact that strengthening will have on the system. Two other major benefits include the short time of application and ability to maintain use of the structure during strengthening $[4,8]$.

In order to increase the flexural load carrying capacity of an existing RC beam, the amount of tensile capacity or compressive capacity must be increased. A relatively new method that has become accepted for strengthening existing structures is through the use of fiber reinforced polymer (FRP) composites. The high strength-to-weight ratio, resistance to corrosion, ease of application, the ability to install FRP without disrupting use of the structure, and relatively low maintenance of FRP make it an attractive composite to be used for strengthening. 


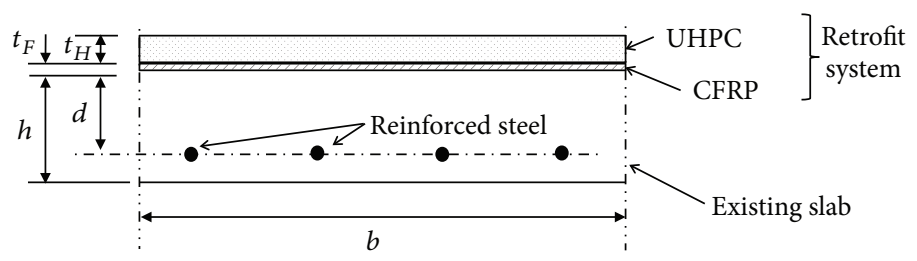

(a)

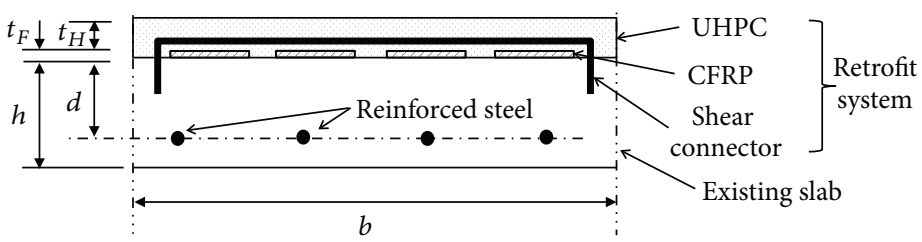

(b)

FIGURE 1: HPC-CFRP retrofit systems for flexural strengthening of the positive moment sections of RC slabs, (a) previously proposed system and (b) the modified system including shear connector.

Current methods of application recommend that the FRP be installed at the location of the extreme tensile fiber at the location of the maximum tension [9]. This application allows the normal concrete to act in compression while the reinforcing steel and FRP act in tension. The FRP is subjected to tensile forces during the entire loading. As the loading progresses, the neutral axis will move toward the compression side of the member and the member will fail, typically due to debonding of FRP prior to crushing of the concrete.

In this study, a hybrid system of high performance concrete (HPC) and carbon fiber reinforced polymer (CFRP) sheets including shear connectors for strengthening of RC slabs is proposed. Three main contributors, CFRP, HPC, and shear connectors, are responsible for the increased capacity of the strengthened RC slabs. To validate this novel strengthening technique at the positive moment section of $\mathrm{RC}$ slab, two one-way slabs were cast. The first slab was an unstrengthened concrete slab which was used as a control. The second slab was cast to mimic the first but featured an overlay of FRP and UHPC after installing shear connectors. Both slabs were treated as simple beams with a region that contained positive bending moment and theoretically no shear.

\section{Proposed Retrofit System}

Previously, a hybrid system composed of HPC and CFRP sheets was proposed to improve the strength and ductility of existing continuous RC slabs by installing the system only to the top of the slab [10] as shown in Figure 1(a) for the positive moment section. Experimental results of the previously proposed system showed that the ultimate load capacity and ductility of the strengthened RC slabs increased by $164 \%$ and $122 \%$, respectively, as compared with the reference slab [10]. However, the slabs strengthened with the previously proposed system failed in shear. This sudden failure was initiated from CFRP debonding from the concrete slab. To ensure ductile failure of flexural members [11], flexural failure design limits of a continuous RC slab according to its moment carrying and shear carrying capacities were proposed to develop a design method of the proposed hybrid FRP-HPC retrofitting system [12].

Here, another retrofit system to induce ductile failure of the strengthened slabs, a hybrid system of CFRP and HPC including shear connectors, is proposed as shown in Figure 1(b). Three main contributors, CFRP, HPC, and shear connectors, are responsible for the increased capacity of the strengthened RC system. The enhancing mechanism for this system was shown in Figure 2. The moment capacity for the strengthened RC slabs can be calculated as

$$
M_{n}=T_{s}\left(j_{1} d\right)+T_{F}\left(j_{2} d\right),
$$

where $T_{s}$ and $T_{F}$ are forces at failure in steel and CFRP, respectively. $j_{1} d$ and $j_{2} d$ are the corresponding moment arm length. It is important to note that the enhancing mechanism of the proposed system at the positive moment sections is valid only when CFRP takes tension at failure.

\section{Experiments}

A concrete having the 28-day characteristic compressive strength of $49 \mathrm{MPa}$ is used for the slabs. Steel rebars having the yield strength of $400 \mathrm{MPa}$ are used to reinforce the slabs. The typical flexural reinforcement bar chosen was number 13 deformed bar which had a cross sectional area of $126.5 \mathrm{~mm}^{2}$. Transverse reinforcement was required to control shrinkage cracks and consisted of number 10 deformed bars with a cross sectional areas of $71 \mathrm{~mm}^{2}$. The slab's size is $130 \mathrm{~mm} \times 900 \mathrm{~mm}$ $\times 2440 \mathrm{~mm}$. The minimum amount of reinforcement was calculated using ACI 318-08 [13]. Details for the RC slab are shown in Figure 3.

For the retrofitted RC slabs, three shear connectors were located as shown in Figure 4. Number 10 rebars having the area of $71 \mathrm{~mm}^{2}$ were used for the shear connectors. 4CFRP sheets were installed and concrete having the 28-day compressive strength of $79 \mathrm{MPa}$ was overlaid. The strength 


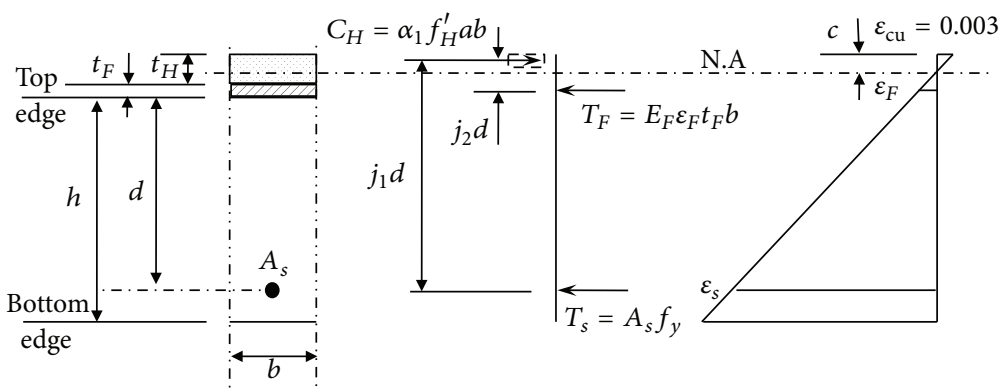

FIGURE 2: Enhancing mechanism of the proposed retrofit system for the positive moment sections of RC slabs.

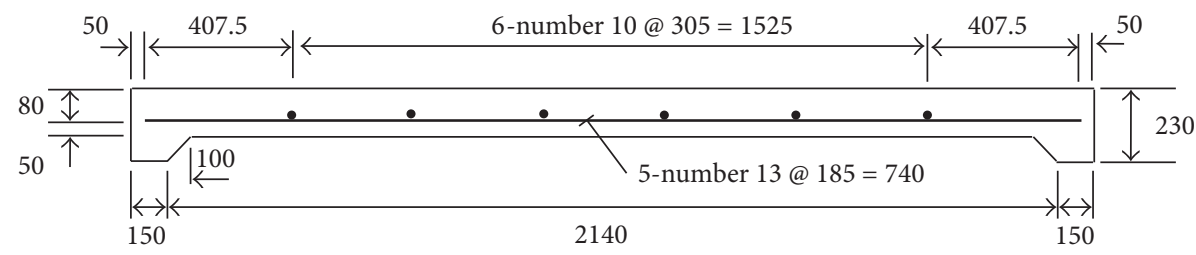

FIGURE 3: Reinforcement details for the control slab specimen having the width of $900 \mathrm{~mm}$.

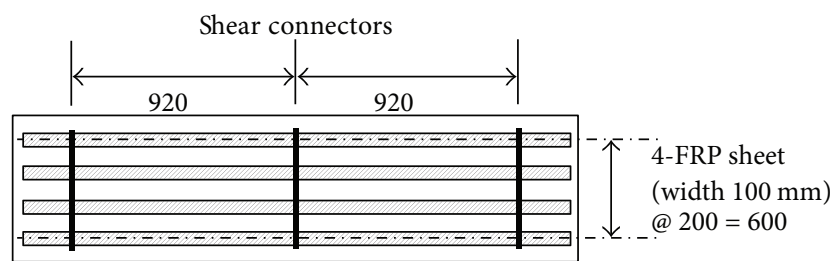

FIGURE 4: Locations of shear connector and CFRP sheets for the proposed retrofit system.

and elastic modulus of CFRP are $600 \mathrm{MPa}$ and $40 \mathrm{GPa}$, respectively. The simply supported test setup for slabs was provided and loaded at two points as shown in Figure 5. The UTM used was capable of applying the maximum force of $5000 \mathrm{kN}$.

\section{Results and Discussions}

4.1. Observations. The full-scale structural test was performed in a successful manner. The slab developed cracks as the loading increased between the loading points. The cracks never developed into full-depth of slab. Some of these cracks can be seen in Figure 6. It shows slab cracking at approximately $20 \mathrm{kN}$ of applied loads. The control slab showed higher failure load of $51.4 \mathrm{kN}$ than was originally calculated with maximum load of $46.7 \mathrm{kN}$. The maximum load applied to the control slab is $34 \%$ higher than the predicted load. The reason for the higher strength of control slab is attributed to the assumption of linear elastic-perfectly plastic behavior of the steel. Testing of the reinforcing steel showed a higher strength in the slab due to strain hardening. The LVDTs had to be reset at different points during the test to continue to provide accurate readings. This maximum midspan deflection of $113 \mathrm{~mm}$ is shown in Figure 7 for the load-deflection $(P-\Delta)$ curve. It can be observed that the structure behaved in a linear elastic fashion until $23 \mathrm{~mm}$ of midspan deflection. The corresponding force at this displacement is $51.4 \mathrm{kN}$. The slope of the $P-\Delta$ curve represents the stiffness of the control slab. The stiffness of the control slab is found to be $10.8 \mathrm{kN} / \mathrm{mm}$ within its elastic limits. The toughness of the system can be calculated by integrating $P$ - $\Delta$ curve. The resulting toughness of the control slab is $5322 \mathrm{kN} \cdot \mathrm{mm}$.

The $P$ - $\Delta$ curve for the retrofitted slab is also shown in Figure 7 with that for control slab. The maximum load in the experiment was $2.7 \%$ higher than the predicted load of $84.8 \mathrm{kN}$. At the load of $40 \mathrm{kN}$, the slab lost capacity due to microbuckling of CFRP sheet as shown in Figure 8 for strain of CFRP. After that, the slab continued carrying higher load until it reached a load of $80 \mathrm{kN}$ when the stress in CFRP was switched from compression into tension. Until the delamination of CFRP at the load of $87.1 \mathrm{kN}$, the slab continued carrying loads. Then, the slab experienced a decrease in capacity and dropped to $73.3 \mathrm{kN}$ due to the delamination of CFRP. Shortly afterwards, the capacity increased to $95.9 \mathrm{kN}$ and the CFRP takes compression until failure as observed in Figure 8. It shows that the shear connector takes loads after delamination of CFRP. The failure load and midspan deflection of the slab were $85 \mathrm{kN}$ and $160 \mathrm{~mm}$, respectively. At this time, it can be approximated as slab fails due to the yielding of the shear connectors.

Horizontal shear failure of the HPC overlay occurred at the midspan. The stiffness of the strengthened slab can be determined as $17.2 \mathrm{kN} / \mathrm{mm}$. This is the stiffness of the retrofitted slab which is about 1.6 times that of the control slab. The toughness of the retrofitted slab was found to be $12114 \mathrm{kN} \cdot \mathrm{mm}$ which is 2.3 times that of the control slab.

The main area of interest was the strain in the CFRP. The strain measurement on the CFRP was critical, as it would verify the system hypothesis that the CFRP sheets stayed in tension during the test and up to failure. As shown in (1), the 


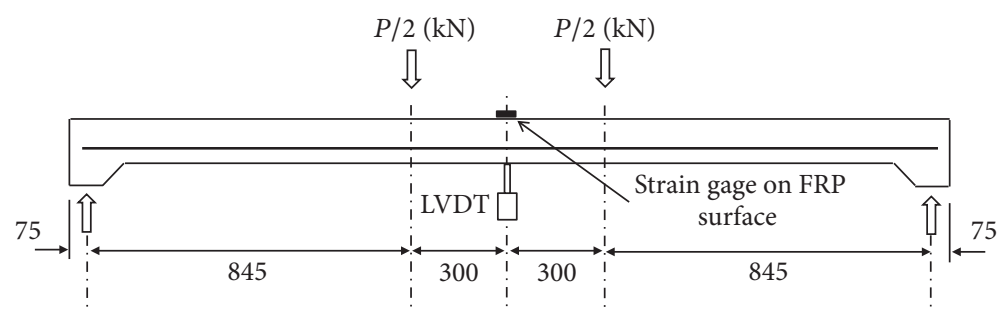

FIgURE 5: Slab loading test setup.

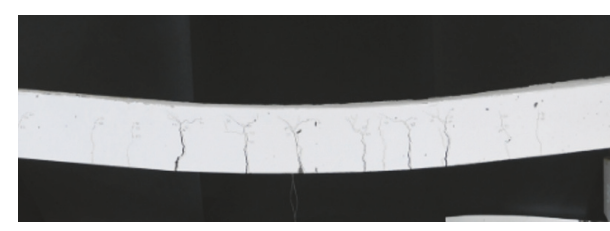

(a)

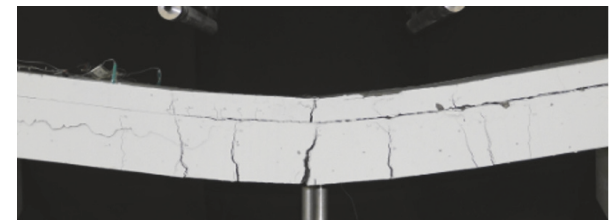

(b)

FIgURE 6: Midspan cracks of slabs at failure, (a) control slab and (b) retrofitted slab.

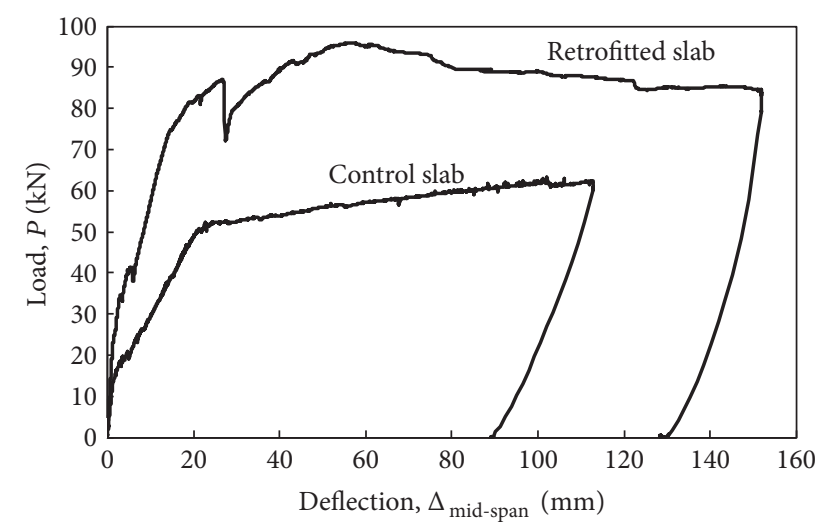

FIGURE 7: Load-deflection curves for the control and the retrofitted slab.

flexural strength increases due to the moment generated by the tension forces in CFRP, $T_{F}$. After delamination of CFRP, shear connectors keep the bonding between the existing RC slab and overlay HPC and it provides ductility until the midspan deflection of $160 \mathrm{~mm}$.

4.2. Finite Element Analysis. The main area of interest was the strain on the CFRP for the proposed retrofit system installed at the positive moment sections as it would verify the proposed system hypothesis that the CFRP sheet takes tension at failure. While CFRP takes tension until the strain of 0.0018 , it did not reach at the debonding strain of 0.006 [9]. Therefore, the retrofitted slabs were analyzed by using nonlinear finite element (FE) analysis. CFRP behavior and the debonding mechanism were investigated. Figure 9 shows the typical analysis model for the retrofit model. For efficient modeling, only $1 / 4$ of the system was modeled by taking advantage of the symmetry.

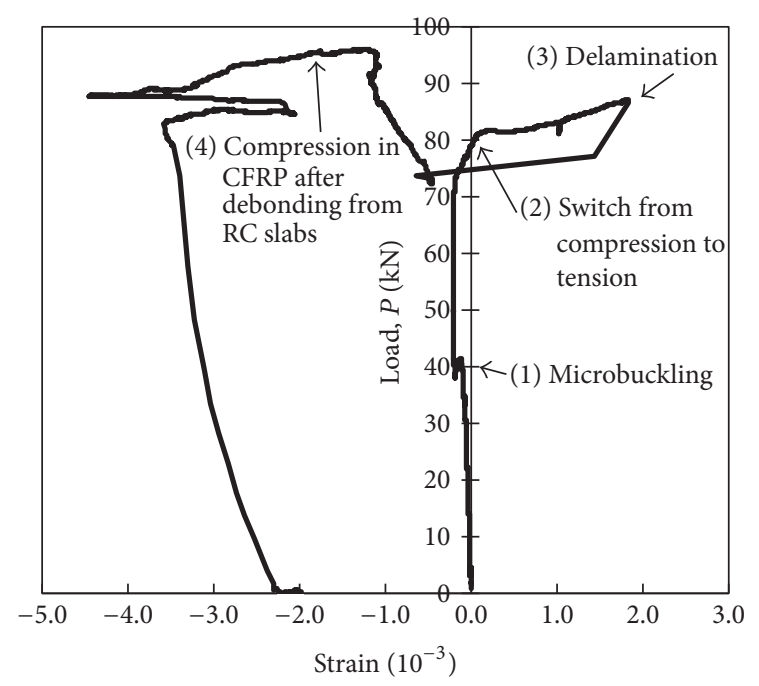

FIGURE 8: Strain evolution in CFRP.

The general purpose structural analysis program ABAUQS was used [14]. The concrete and HPC were modeled using 8-node solid elements with reduced integration point. For CFRP sheet and rebar, 4-node shell and 2-node truss element were used for the analysis, respectively, as shown in Figure 9. The rebar and CFRP sheet were embedded into the concrete by using EMBEDED option in ABAQUS [14]. Thus, rebar and CFRP sheet are perfectly bonded to the concrete. For CFRP sheet, this assumption is reasonable before the tensile strain of the CFRP is smaller than 0.006, where strain of 0.006 in CFRP sheet represents the debonding strain [9]. Analysis of concrete includes many nonlinear responses such as concrete cracking. Thus, to ensure the convergence of the solution, STABILIZE option in ABAQUS is used in this study [14]. STABILIZE option provides an automatic mechanism for stabilizing unstable quasi-static problems 


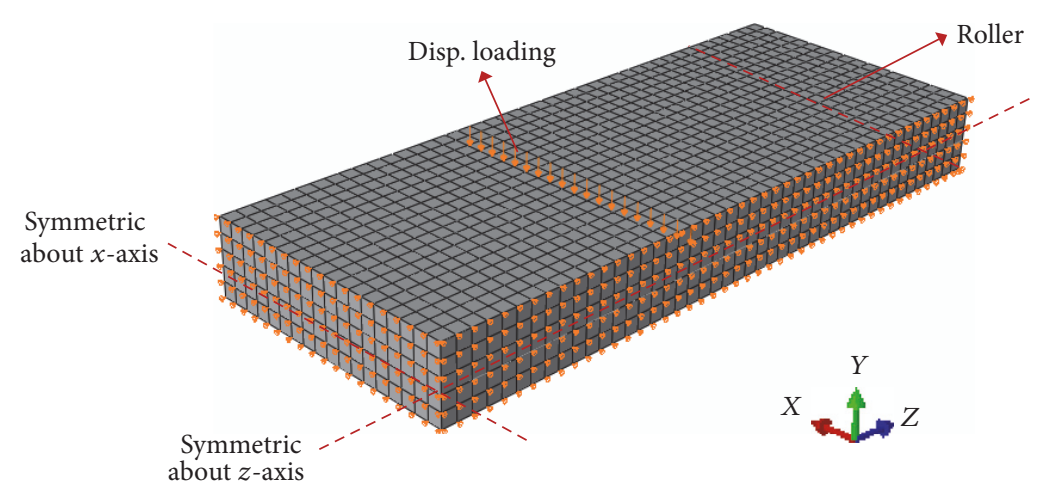

(a)

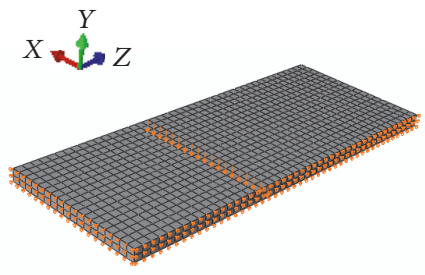

UHPC (8-node solid element)

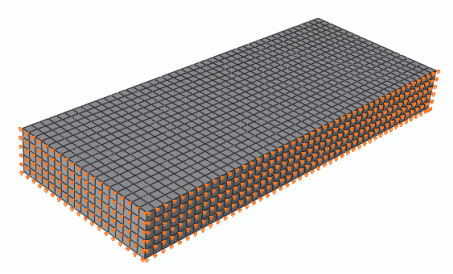

Concrete (8-node solid element)

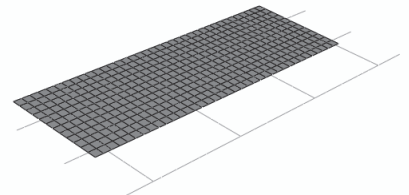

Reinforcing bar (2-node truss element) FRP sheet (4-node shell element)

(b)

FIGURE 9: FE models: (a) FE model and boundary conditions and (b) elements for HPC-CFRP retrofit model.

through the automatic addition of volume-proportional damping to the model [14]. The translation in directions 1 and 3 were restrained to simulate the symmetric pane for $x$ and $z$-axis, as shown in Figure 9. The bottom line of the end of the analysis model was restrained in $y$ direction to model the roller support. Then, a monotonic displacement loading was applied.

Figure 10 shows the comparisons of the load-displacement relationship for HPC retrofit model for verification of FE model with observation. For the retrofitted model, overall stiffness and ultimate strength of FE analysis model were matched well with the observation. Analysis was performed up to approximately $60 \mathrm{~mm}$ of deflection, and the model was yielded around $14.3 \mathrm{~mm}$ of deflection. For the yield point (deflection $=14.4 \mathrm{~mm})$, the maximum tensile stress in the CFRP sheet was $56 \mathrm{MPa}$. Thus, the corresponding tensile strain of the CFRP is approximately 0.0014 $(56 \mathrm{MPa} / 40 \mathrm{GPa})$, and it is similar to the observed strain of 0.0016 . Figure 11 represents the Von-Mises stresses in the analysis model at the yield point. As shown in Figure 11, it can be found that the tensile stresses were developed in CFRP sheets. Thus, the neutral axis exists inside of the UHPC part when UHPC retrofit model is yielded. The delamination of CFRP with the substrate slab might be due to the cracks on the top of substrate slab as shown in Figure 11 for the stress distribution of substrate slab.

\section{Conclusions}

Considering the difficulty of the accessibility and installation of FRP laminates to the underside of RC slabs and bridge decks for flexural strengthening, a hybrid composite system,



FIGURE 10: FE model verification.

which consists of UHPC, CFRP, and shear connectors, was proposed. The system is applied to the top surface of the floor slabs or bridge decks and it is introduced to improve the flexural carrying capacity of the existing RC floor slab and bridge decks. Using simply supported slab specimens, only positive moment section was examined to verify the effectiveness of the proposed system experimentally and 

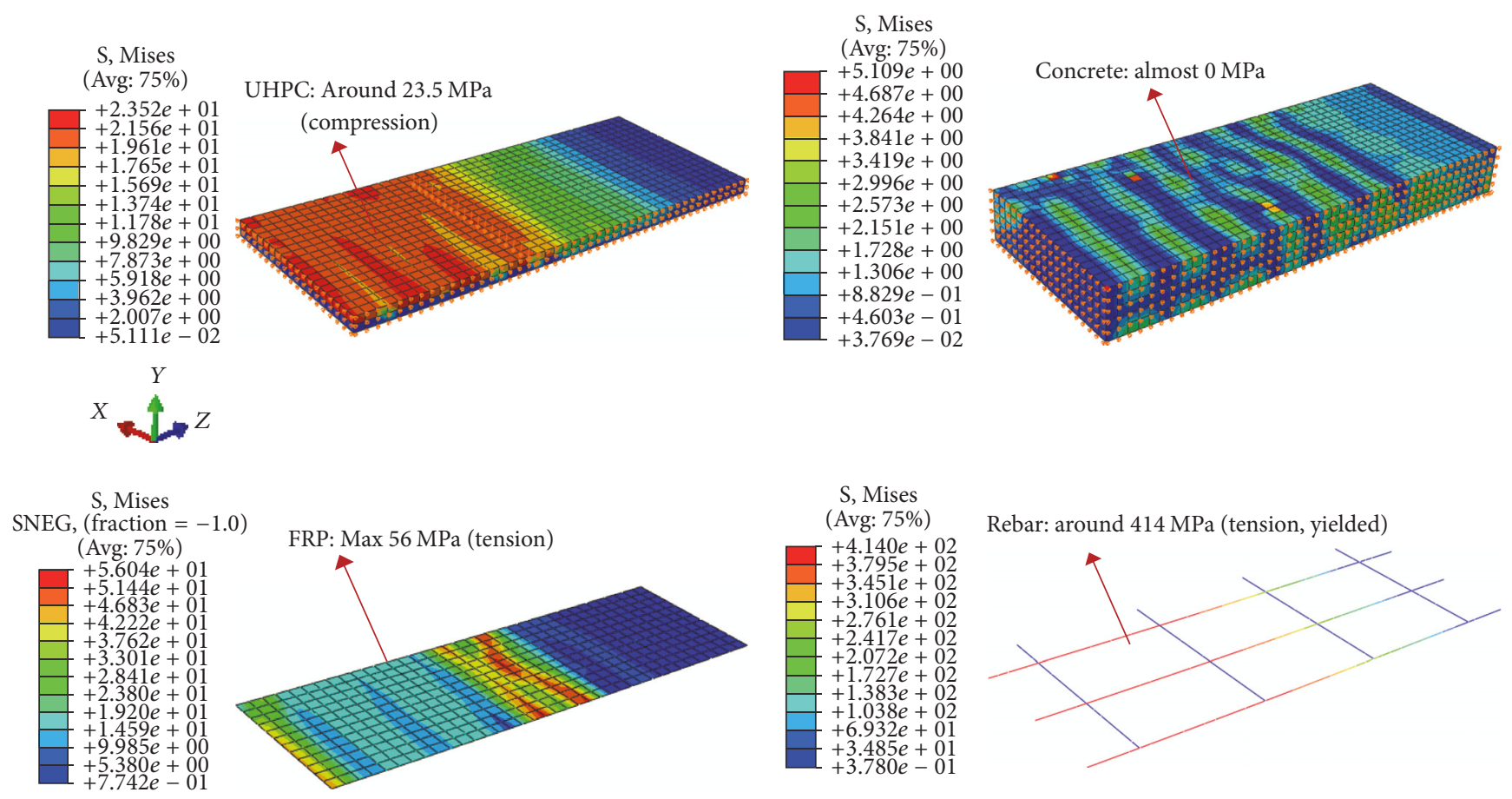

FIGURE 11: Stresses in HPC overlay at yield point.

numerically. The proposed strengthening system increased the ultimate load carrying capacity of the slab by $70 \%$, the stiffness by $60 \%$, and toughness by $128 \%$. The efficiency of shear connectors on ductile behavior of the retrofitted slab was also confirmed.

\section{Conflicts of Interest}

The authors declare that there are no conflicts of interest regarding the publication of this paper.

\section{Acknowledgments}

This research was supported by Korea Agency for Infrastructure Technology Advancement (KAIA) (Grant no. 16CTAPC097358-02) funded by Ministry of Land, Infrastructure and Transport (MOLIT) of Korea government.

\section{References}

[1] K. M. Mosalam and A. S. Mosallam, "Nonlinear transient analysis of reinforced concrete slabs subjected to blast loading and retrofitted with CFRP composites," Composites Part B, vol. 32, no. 8, pp. 623-636, 2001.

[2] A. S. Mosallam and K. M. Mosalam, "Strengthening of two-way concrete slabs with FRP composite laminates," Construction and Building Materials, vol. 17, no. 1, pp. 43-54, 2003.

[3] M. I. Ary and T. H.-K. Kang, "Shear-strengthening of reinforced \& prestressed concrete beams using FRP: part I-review of previous research," International Journal of Concrete Structures and Materials, vol. 6, no. 1, pp. 41-47, 2012.
[4] C. J. Fleming and G. E. M. King, "The development of structural adhesives for three original uses in South Africa," in Proceedings of the RILEM International Symposium, Synthetic Resins in Building Construction, pp. 75-92, Paris, France, 1967.

[5] P. H. Emmons, A. M. Vaysburd, and J. Thomas, "Strengthening concrete structures, Part II," Concrete International, vol. 20, no. 4, pp. 56-60, 1998.

[6] J. Nam, H. Kim, S. Kim, N. Yi, and J. J. Kim, "Numerical evaluation of the retrofit effectiveness for GFRP retrofitted concrete slab subjected to blast pressure," Composite Structures, vol. 92, no. 5, pp. 1212-1222, 2010.

[7] J. Li, C. Wu, H. Hao, Y. Su, and Z. Liu, "Blast resistance of concrete slab reinforced with high performance fibre material," Journal of Structural Integrity and Maintenance, vol. 1, no. 2, pp. 51-59, 2016.

[8] S. Rizkalla, T. Hassan, and N. Hassan, "Design recommendations for the use of FRP for reinforcement and strengthening of concrete structures," Progress in Structural Engineering and Materials, vol. 5, no. 1, pp. 16-28, 2003.

[9] ACI Committee 440, "Guide for the design and construction of externally bonded FRP systems for strengthening concrete structures," Tech. Rep. ACI 440.2R-08, Farmington Hills, Mich, USA, 2008.

[10] A. Mosallam, M. M. Reda Taha, J. J. Kim, and A. Nasr, "Strength and ductility of RC slabs strengthened with hybrid high-performance composite retrofit system," Engineering Structures, vol. 36, pp. 70-80, 2012.

[11] J. G. MacGregor and J. K. Wight, Reinforced Concrete: Mechanics and Design 5th, Prentice Hall, USA, 2005.

[12] J. J. Kim, H.-C. Noh, M. M. Reda Taha, and A. Mosallam, "Design limits for RC slabs strengthened with hybrid FRP-HPC retrofit system," Composites Part B, vol. 51, pp. 19-27, 2013. 
[13] ACI Committee 318, "Building Code Requirements for Structural Concrete (ACI 318-05) and Commentary (318R-05)," International Journal of Cement Composites and Lightweight Concrete, American Concrete Institute, Farmington Hills, USA, 2005.

[14] ABAQUS, "ABAQUS analysis user's manual version 6.9-2", Dassault Systemes Simulia Corp., Providence, RI, USA, 2009. 

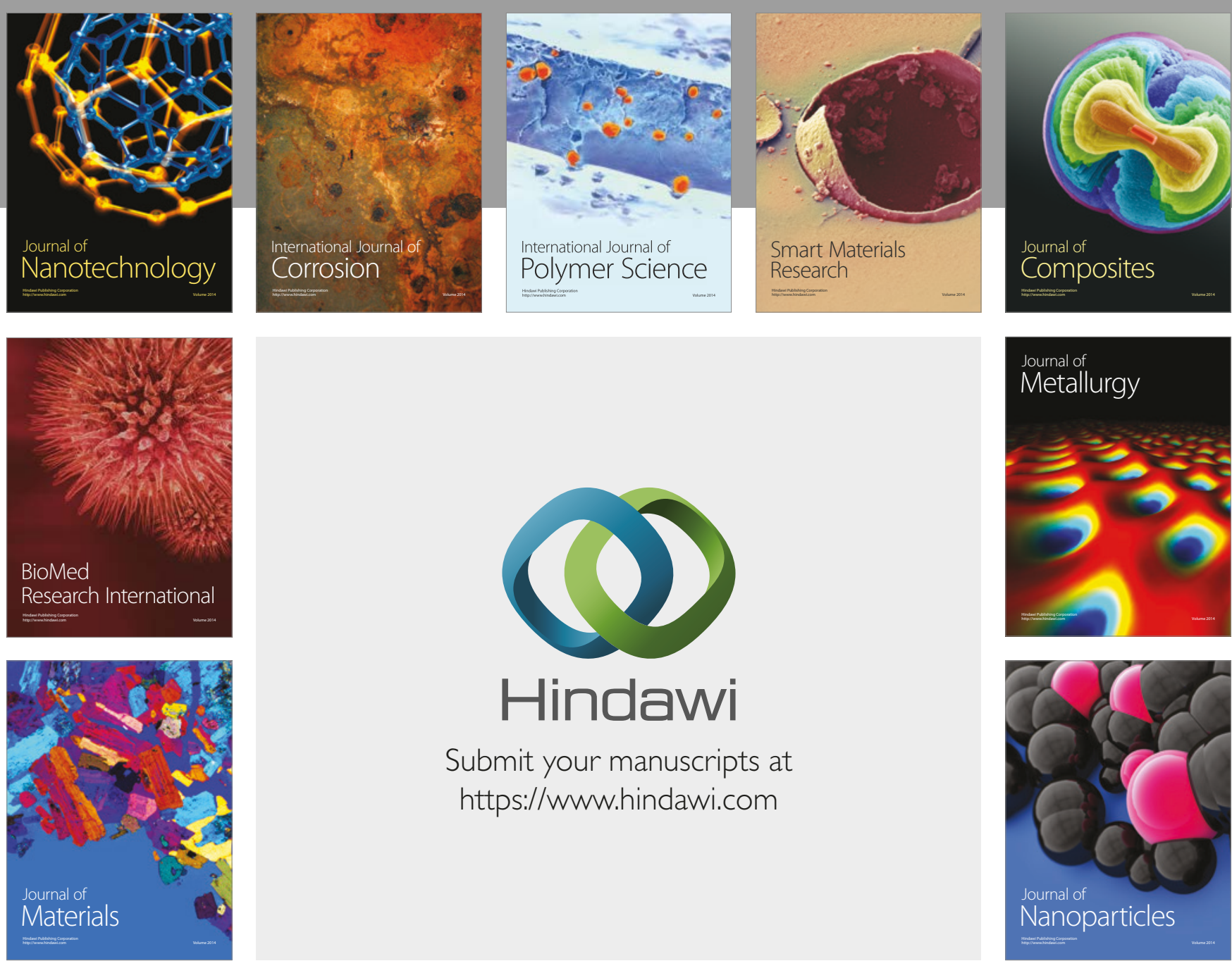

\section{Hindawi}

Submit your manuscripts at

https://www.hindawi.com
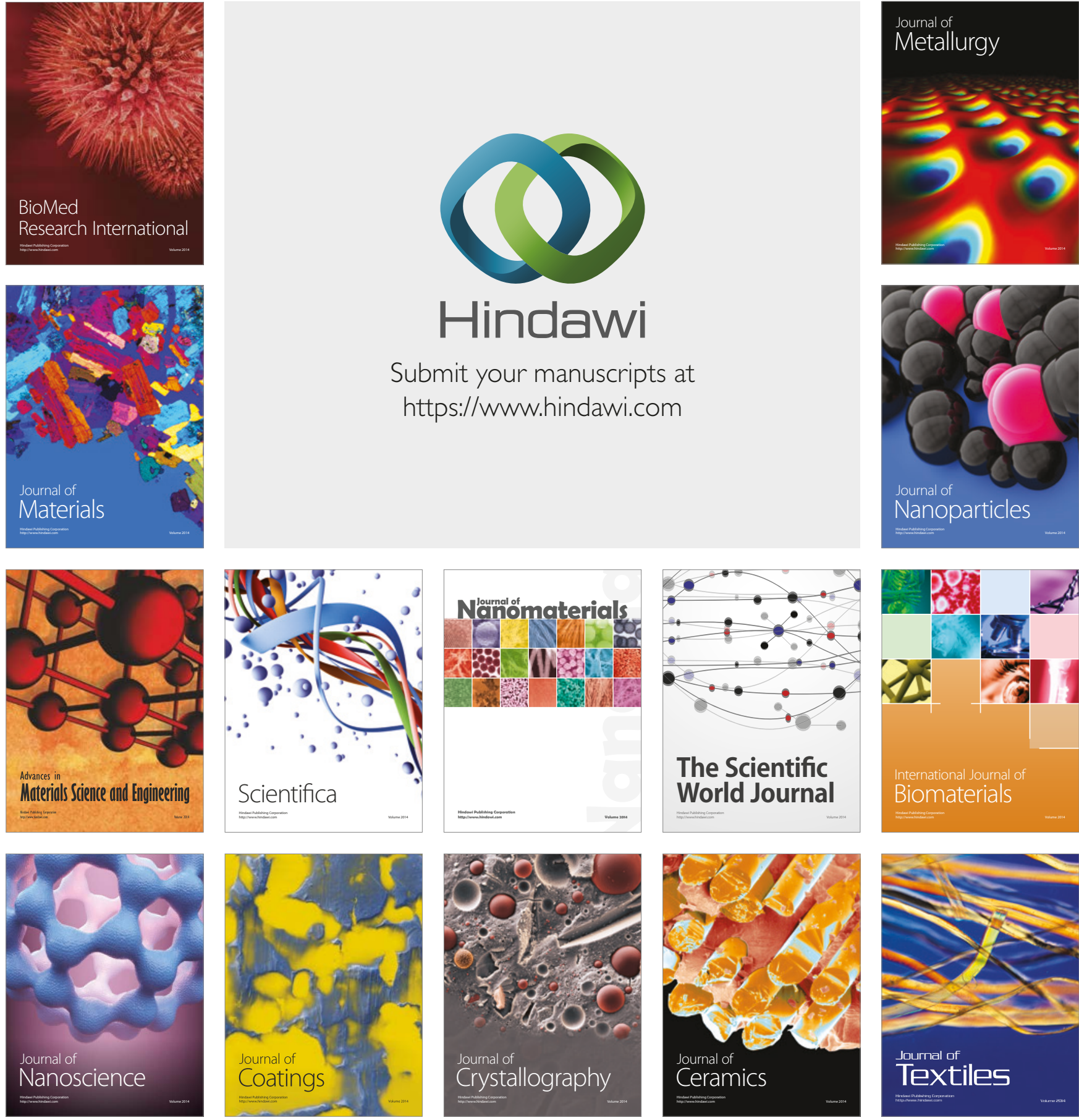

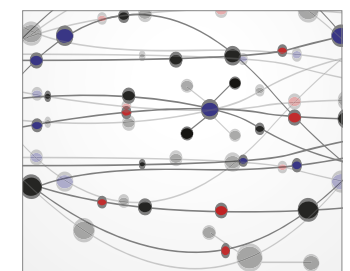

The Scientific World Journal
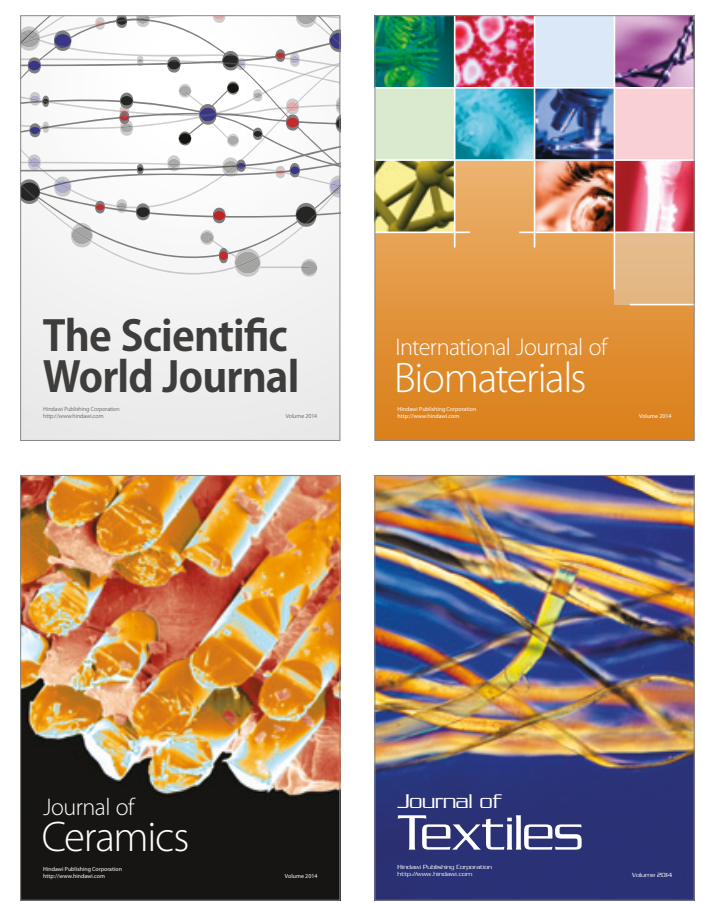